\title{
Signals Regulating Vesicle Trafficking in Paramecium Cells
}

\author{
Helmut Plattner
}

\begin{abstract}
Most data available from Paramecium, fewer from Tetrahymena, disclose essentially the same principles of signaling as in metazoans up to man. Microtubules serve for long-range signaling, whereas SNARE proteins, $\mathrm{H}^{+}$-ATPase, GTPases and actin provide short-range molecular signals, with $\mathrm{Ca}^{2+}$ as a most efficient, locally and spatially restricted signal particularly for membrane fusion. This is enabled by the strategic positioning of $\mathrm{Ca}^{2+}$-release channels, type $\mathrm{InsP}_{3}$ receptors and ryanodine-receptor-like proteins, also in ciliates. In Paramecium, the most evident trafficking routes encompass exo-/endocytosis, endo-/phagocytosis and the contractile vacuole complex. The high specificity, precision and efficiency of vesicle trafficking regulation in ciliates is facilitated by their highly regular, epigenetically controlled cell structure, with firmly installed microtubular rails.
\end{abstract}

\subsection{Basic Aspects of Vesicle Trafficking and Signaling Pathways in Ciliates}

Ciliates are well designed cells, with a cell cortex composed of unit fields called kinetids, about $1 \times 2 \mu \mathrm{m}$ in size. Each kinetid possesses a cilium (or two) in its center and intermittently positioned dense core-secretory organelles. These are trichocysts in Paramecium and mucocysts in Tetrahymena- the most intensely studies genera. This epigenetically controled surface pattern (Beisson and Sonneborn 1965; Wloga and Frankel 2012) entails important consequences for signaling, e.g. by the universal second messenger, $\mathrm{Ca}^{2+}$, as it allows for alternative activation of cilia and of vesicle exocytosis, respectively, due to strict local and temporal signal confinement (Klauke and Plattner 1997; Husser et al. 2004). Exocytosis is an example of short-range signaling enabled by a pre-assembled signaling machinery and a local $\mathrm{Ca}^{2+}$ impulse.

H. Plattner $(\varangle)$

Department of Biology, University of Konstanz, P.O. Box M625, 78457 Konstanz, Germany

e mail: helmut.plattner@uni konstanz.de 
Microtubules emanating from ciliary basal bodies act as long-range signals for the transport of trichocysts to docking sites (Aufderheide 1977; Glas-Albrecht et al. 1991). Close to basal bodies, parasomal sacs serve for formation of clathrin-coated endosomes (Elde et al. 2005), alternating with constitutive exocytosis of surface coat materials (Flötenmeyer et al. 1999). Other landmarks in the cell cortex are the cytostome from where phagosomes pinch off, fed by acidosomes (late endosomes) and recycling vesicles originating from the cytoproct - the site of spent food vacuole release (Allen and Fok 2000). Again, microtubules form a long-range signaling system in this "ventral" part of the cell by guiding vesicles to the nascent food vacuole. The outlets of the two contractile vacuole complexes are positioned "dorsally", also under epigenetic control.

Three vesicle trafficking pathways are recognizable: (i) from endoplasmic reticulum via Golgi apparatus to the cell surface for the exocytotic route, paralleled by a reverse endocytotic pathway via endosomes for membrane recycling and/or degradation in lysosomes; (ii) the phagocytotic pathway, coupled to endocytosis and recycling, for digestion of food particles; finally, (iii) the contractile vacuole complex for periodic expulsion of an excess of water and ions (Allen and Naitoh 2002). This counteracts the rapid permeation of water and $\mathrm{Ca}^{2+}$ and-beyond pulsation activity - also involves less overt membrane dynamics and signaling (Plattner 2015c).

Before genomic databases became available, Allen and Fok (2000) have pioneered the field of vesicle trafficking in Paramecium by using organelle-specific monoclonal antibodies for immunolocalization studies (http://www5.pbrc.hawaii. edu/allen/). Subsequently molecular biology allowed for more stringent molecular identification, localization and gene silencing of key players in signal-based vesicle trafficking. Short-range signals include SNARE proteins, the SNARE-specific chaperone NSF, $\mathrm{H}^{+}$-ATPase/pump, actin, $\mathrm{Ca}^{2+}$-release channels (CRC), as analyzed in Paramecium (reviewed by Plattner 2010a), and small GTPases analyzed in Tetrahymena (Bright et al. 2010). SNAREs stand for "soluble $N$-ethylmaleimide sensitive factor (NSF) attachment protein receptors", NSF being a SNARE-specific chaperone (Rothman 2014; Südhof 2014). SNAREs, together with Rab-type monomeric GTP-binding proteins/GTPases and their organelle-specific binding proteins (Grosshans et al. 2006) and high sensitivity $\mathrm{Ca}^{2+}$-binding proteins are important for short-range signaling enabling membrane interaction and fusion (Rothman 2014; Südhof 2014).

Note that genes and proteins of Paramecium tetraurelia, are designated with the prefix "Pt", e.g. PtSyb for synaptobrevin. As there are subfamilies of variable size, a designation may be PtSyb5-1. The prefix Pt is important since synaptobrevins are difficult to correlate with their equivalents up to mammals with regard to localization and function. Although this is more easy, e.g. with syntaxins, we maintained this nomenclatorial principle throughout. For CRCs we used a comparable designation, for instance, PtCRC-IV-1 for a subfamily member. Considering the number of paralogs (also called ohnologs when arisen by whole genome duplications) in a protein/gene family of $P$. tetraurelia it was not possible to analyse them all and their localization and function may be similar or even identical. Therefore, in this 
review, the types of subfamily members are usually not specified. More details can be retrieved from the original publications and reviews cited, e.g. Plattner (2010a, b) for SNAREs and Plattner and Verkhratsky (2013) for CRCs.

Figure 6.1a illustrates the general principle of signalling for vesicle trafficking, Fig. 6.1b the requirement of a strictly confined $\mathrm{Ca}^{2+}$ signal for membrane fusion, Fig. 6.1c the molecular interactions during intracellular vesicle trafficking, as exemplified by food vacuole (phagolysosome) formation, and Fig. 6.1d the particular situation of an exocytosis site in ciliates.

\subsection{Long-Range Trafficking Signals}

Since biogenesis of the surface membrane complex requires proper positioning of components, such as cilia, parasomal sacs and trichocysts, one may ask for cause and consequence. On the one hand one may ask for the causation of this regular arrangement and, on the other hand, for its consequences for signalling processes. Reversing this arrangement by spontaneous misplacement in Euplotes (Frankel 1973) or experimentally by microsurgery in Paramecium (Beisson and Sonneborn 1965) maintains and transfers such local disorientation, thus indicating epigenetic regulation of surface pattern formation and resulting signalling (Plattner 2015a).

Analysis of surface pattern formation has revealed several crucial components of ciliary basal bodies (Beisson and Jerka-Dziadosz 1999). Saltatory docking of trichocysts (Aufderheide 1977) along microtubules originating at ciliary basal bodies (Plattner et al. 1982; Glas-Albrecht et al. 1991), quite unusually, occurs in plus-to-minus direction of microtubules - a phenomenon maintained in evolution, e.g. in mammalian epithelia and T-lymphocytes (Griffiths et al. 2010). Some possible mechanisms relevant for the distinct positioning of the contractile vacuole complexes, also microtubule-based, have been discussed recently (Plattner 2013, 2015c).

Important parts of the phagocytotic pathways and delivery of recycling vesicles in ciliates are also guided by microtubules. Crucial work from Allen and Fok (2000) revealed that recycling vesicles travel from the cytoproct to the cytostome for reuse, as shown with Paramecium multimicronucleatum (Fok and Allen 1993) and Tetrahymena thermophila (summarized by Wloga and Frankel 2012).

In conclusion, pre-established microtubular arrays, together with appropriate motor proteins, allow for long-range signaling and, thus, render vesicle trafficking very efficient. Since many types of vesicles bounce around in the cytoplasm one has to ask what molecular signal makes a vesicle jump onto the bandwagon suitable for delivery to its final address. In the end this is determined by vesicle-resident proteins, e.g. an "early endosome antigen" (EEA) — a short-range signal, as described below.

Prerequisite to the strict signalling phenomena in the cell cortex is the targeted delivery of vesicles and their membrane components to proper sites. The selective expression pattern during reciliation following deciliation, e.g. in T. thermophila 
(a)
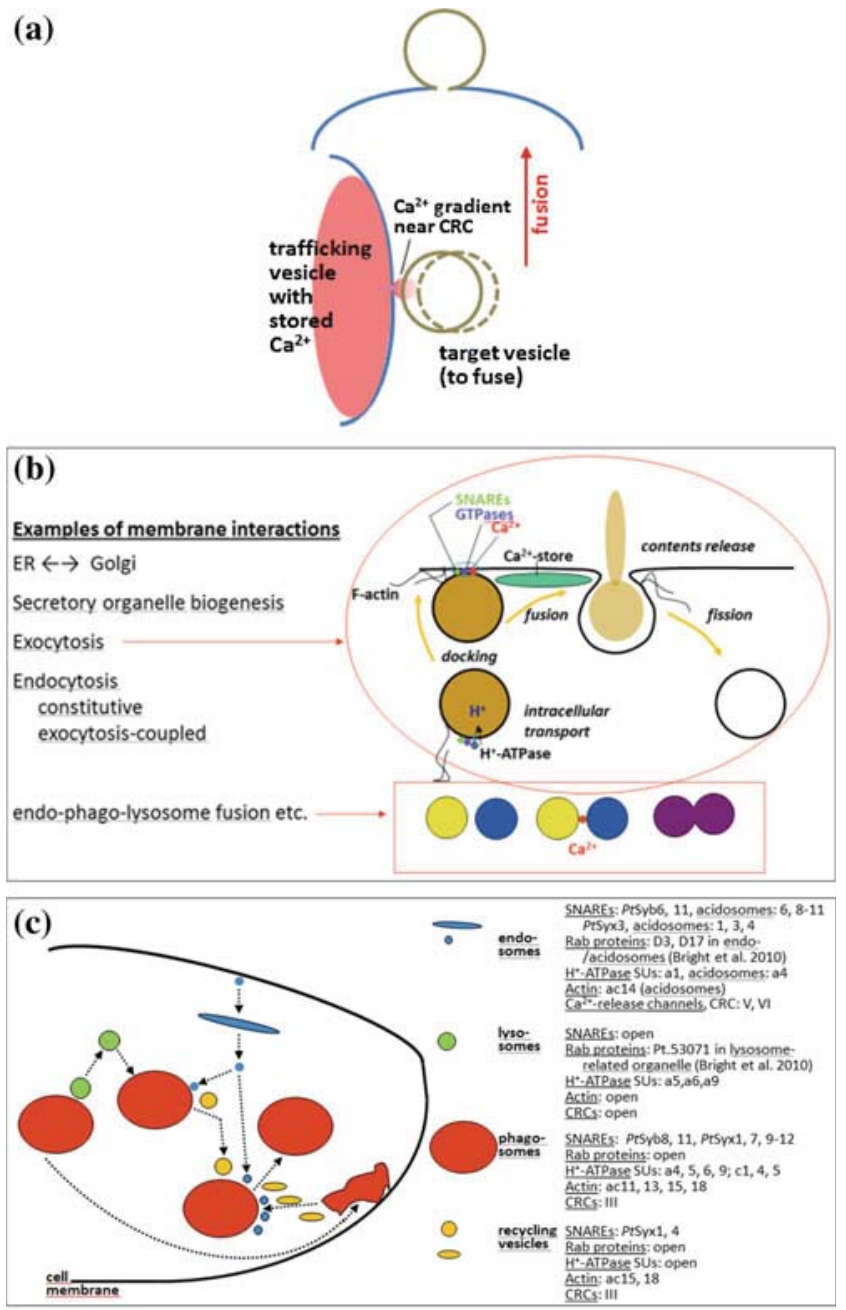

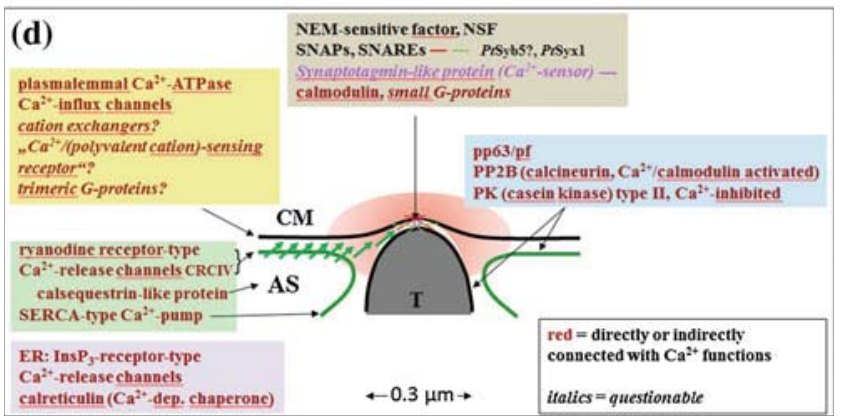


4 Fig. 6.1 a Principles of vesicle/membrane interaction, with the involvement of SNAREs, GTPases, $\mathrm{H}^{+}$ATPase, actin and $\mathrm{Ca}^{2+}$. Acidification of the vesicle lumen by the organellar $\mathrm{H}^{+}$ ATPase signals binding of additional components, leading to vesicle docking at a target membrane and fusion upon a $\mathrm{Ca}^{2+}$ signal. This principle applies not only to exocytosis (top) but also to intracellular membrane interactions (bottom). b Illustrates the local restriction of $\mathrm{Ca}^{2+}$ signals for membrane fusion, e.g. by release via local CRCs. c Vesicle trafficking and molecules involved in the endo /phagocytotic process. At the right, key players relevant for the respective steps are listed. Note, for instance, the exchange of actin, CRC and SNARE isoforms. d Components assembled at and around a trichocyst docking site include not only proteins relevant for docking and fusion, but also for $\mathrm{Ca}^{2+}$ storage in, and release from alveolar sacs (AS), as well as $\mathrm{Ca}^{2+}$ pumps, $\mathrm{Ca}^{2+}$ binding proteins and proteins relevant for energetic aspects, such as pp63/pf, PP2B and a casein kinase, shown at the right/center. Green arrows indicate $\mathrm{Ca}^{2+}$ flux upon stimulation. Some components, listed with a question mark, require identification in ciliates. $\mathrm{AS}=$ alveolar $\mathrm{sac}, \mathrm{CM}=$ cell membrane, $\mathrm{T}=$ trichocyst. For further details, see text and Plattner (2016) (Color figure online)

(Miao et al. 2009), can provide insight into the relevance of individual components. Frequently this is pinpointed by following up in ciliates the relevance of mutations underlying mammalian ciliary pathology, as summarized previously (Simon and Plattner 2014). It should be noted that vesicles are not delivered into cilia in any system analysed. Unexpectedly we observed a ring of PtSyb10 around the ciliary basis (Schilde et al. 2010). Since synaptobrevins are normally harbored in vesicles, rather than in target membranes (see below) this might indicate retention due to excessive vesicle delivery, whereas this normally seems to be counterbalanced by membrane retrieval.

Another aspect is that $\mathrm{Ca}^{2+}$ can separately regulate widely different processes, such as trichocyst exocytosis and ciliary activity. Why is a cell then not confused when stimulated? Normally there is no spill-over of $\mathrm{Ca}^{2+}$ from cilia to exocytosis sites which, therefore, remain inactive (Husser et al. 2004). However, the opposite process does take place when a predator attacks a Paramecium cell. In consequence, explosive local trichocyst release keeps the predator at a distance and ciliary reversal allows the potential prey to rapidly escape (Knoll et al. 1991a). Both processes depend on $\mathrm{Ca}^{2+}$ and spillover of $\mathrm{Ca}^{2+}$ into cilia (Husser et al. 2004) allows, in this case, to bypass the physiological activation of ciliary reversal. Normally this is induced by cell membrane depolarization and $\mathrm{Ca}^{2+}$ influx selectively into cilia via voltage dependent channels [For review see Plattner and Klauke (2001) and Plattner (2014)]. Beyond this exceptional situation of a long-range $\mathrm{Ca}^{2+}$ signal there are several mechanisms to confine a $\mathrm{Ca}^{2+}$ signal very strictly (Sect. 6.3).

\subsection{Short-Range Trafficking Signals}

\subsubsection{General Aspects}

Evidently integral membrane proteins can serve as local landmarks for specific interaction with a partner membrane (Fig. 6.1a). This applies to SNAREs, anchored 
by their carboxy-terminal region, as well as to $\mathrm{C} 2$-type high sensitivity $\mathrm{Ca}^{2+}$-sensor proteins, type synaptotagmin, inserted by their amino-terminal region. Both are crucial for membrane fusion (In Paramecium we have found only synaptotagmin-like proteins, still to be characterized; see Sect. 6.3.3). For a summary of key players in membrane recognition and fusion, see Plattner (2010a). Also some soluble proteins, type Rab, have to be locally available. As mentioned, they bind to organelle-specific integral membrane proteins (essentially unknown in ciliates). All these molecules have to match with their counterparts in the target membrane.

$\mathrm{Ca}^{2+}$ for signaling originates either from release from a nearby store, or interacting vesicles contain $\mathrm{Ca}^{2+}$ themselves and are able to release $\mathrm{Ca}^{2+}$ via CRCs integrated in their membrane (Plattner 2015b); see Fig. 6.1b. Cytosolic $\mathrm{Ca}^{2+}$ concentration has to rise very locally and for a very restricted time, for different reasons (Plattner and Verkhratsky 2015). First, $\mathrm{Ca}^{2+}$ at too high concentrations is toxic; second, $\mathrm{Ca}^{2+}$ diffuses rapidly; third its concentration is rapidly downregulated by binding to $\mathrm{Ca}^{2+}$-binding proteins, and over longer times by sequestration and extrusion from the cell; fourth, its effect depends of concentration in a supralinear function (Neher 1998a). All this calls for microdomain regulation in ciliates (Klauke and Plattner 1997; Plattner and Klauke 2001), just as in neurons (Neher 1998b). Local $\mathrm{Ca}^{2+}$ signals for membrane fusion are so short-lived that their actual size and duration can only be extrapolated from intracellularly applied $\mathrm{Ca}^{2+}$ chelators with different binding and time constant (Neher 1998a, b). In Paramecium, $\mathrm{Ca}^{2+}$ for trichocyst exocytosis comes from alveolar sacs (Sect. 6.3.3), the well established cortical stores (Stelly et al. 1991; Hardt et al. 2000; Plattner and Klauke 2001). Local values of $\sim 5 \mu \mathrm{M}$ are required for exocytosis (Klauke and Plattner 1997). Considering that, in mammalian cells, most trafficking organelles contain $\mathrm{Ca}^{2+}$ themselves (Hay 2007) and the occurrence of CRCs in such organelles (except trichocysts) in Paramecium (Ladenburger and Plattner 2011), one can reasonably assume that $\mathrm{Ca}^{2+}$ signaling in microdomains occurs throughout vesicle trafficking pathways also in ciliates. For any further discussion, see Plattner (2014).

Some essential aspects of signaling are outlined in Fig. 6.1a. A vesicle contains SNARE proteins (called v- or R-SNAREs due to an R [Arg] residue in the center of the SNARE domain). For docking, a target membrane has to contain a matching set of t-/Q-SNARES (Q = Glu). SNAP-25 is an additional SNARE that, because of its wide distribution throughout the Paramecium cell is hardly appropriate to further specify short-range signaling. As mentioned, additional specificity is provided by the reversible binding of monomeric GTP-binding proteins (GTPases type Rab for vesicle trafficking), as analysed in Tetrahymena (Bright et al. 2010). These in turn bind to organelle-specific residents proteins (hardly identified in ciliates). A total of 44 SNAREs, v-/R- (Schilde et al. 2006, 2010) and t-/Q-SNARES (Kissmehl et al. 2007) have been assigned in Paramecium to specific organelles, some containing more than one type, including some rather similar ohnologs (Plattner 2010b) due to 
recent whole genome duplications. 57 Rabs are reported from Tetrahymena (Bright et al. 2010).

The activity of Rabs is governed by activating and inhibitory proteins (hardly known from ciliates), respectively. In higher eukaryotes their attachment to the respective target membrane depends on the luminal $\mathrm{pH}$ value (Hurtado et al. 2006). Concomitantly, vesicles undergoing trafficking contain a $\mathrm{H}^{+}$-ATPase (Mellman 1992). The conformational change of the $\mathrm{H}^{+}$-ATPase/pump resulting from the actual luminal acidification enables the binding of Rab regulators and Rab proteins, probably also in ciliates. Here, we also find this multimeric $\mathrm{H}^{+}$-ATPase in the organelles undergoing trafficking (Wassmer 2005, 2006, 2009). Particularly remarkable is the unprecedented number of a-subunit isoforms which allows for the attachment of the catalytic V1 part to the membrane-integrated $\mathrm{H}^{+}$-conducting base piece, V0; both, V0 and V1 are a complex of variable monomers. The high number of theoretical combinations with the a-subunit may allow for a range of subunit combinations for local requirements. Similarly organelle-specific CRCs may account for specific local requirements. Work with higher eukaryotes suggests that targeting of some of the components under consideration for short-range signalling is mutually interdependent, as reviewed previously (Plattner 2010a).

\subsubsection{Signaling During the Endo-Phagolysosomal Cycle}

Figure 6.1c outlines vesicle trafficking and signalling molecules involved in food vacuole (phagolysosome) formation. Already before the molecular era, Allen and Fok (2000) have elucidated the principal pathways of phagocytosis in Paramecium multimicronucleatum.

Formation of food vacuoles starts at the cytostome. Here, the cell membrane seems to bulge in; in reality this part of the cell membrane-in the absence of alveolar sacs, ciliary basal bodies and of trichocysts-is extended by recycling vesicles. These are delivered from spent food vacuoles after contents discharge at the cytoproct and by other recycling vesicles originating from progressed stages of food vacuoles. The nascent vacuole becomes a phagosome which is a non-acid organelle devoid of $\mathrm{H}^{+}$-ATPase. Only after pinching off, late endosomes, called acidosomes because of their endowment with $\mathrm{H}^{+}$-ATPase, fuse with the phagosome (Allen et al. 1993). On their way through the cell (cyclosis) food vacuoles fuse with lysosomes and, thus, become phagolysosomes which digest food particles. At a later stage, lysosomal components are retrieved and the spent food vacuole releases indigestible materials at the cytoproct (Allen and Fok 2000). When stained with permeable acidity markers, which are retained in protonated form and change color depending on luminal $\mathrm{pH}$, a color change indicates the sequence: neutral $\rightarrow$ acid $\rightarrow$ neutral (Wassmer et al. 2009). 
The sequence of events described is supported by long-range and short-range, molecular signaling. Here, like in other acidic compartments, such as endosomes, occurrence of an $\mathrm{H}^{+}$-ATPase was demonstrated (Fok et al. 2002; Wassmer et al. 2009). As mentioned, changing acidification also implies change of Rab protein binding (Hurtado-Lorenzo et al. 2006) at the organelle surface. Changing binding partners, from endosome to phagolysosome, are indicated in Fig. 6.1c. Whereas this background information mainly comes from Paramecium (P. multimicronucleatum for classical cell biology, P. tetraurelia for molecular biology), data concerning changing association of Rab proteins throughout the digesting cycle come from $T$. thermophila, with a side glance on P. tetraurelia (Bright et al. 2010).

Figure 6.1c summarizes what is known about the changing isoforms of SNAREs, $\mathrm{H}^{+}$-ATPase subunits, actin and CRCs along the endo-phagolysosomal pathway, as determined in our laboratory, supplemented by data on changing Rab proteins collected by the Turkewitz laboratory (Bright et al. 2010). This comprehensive work reveals extensive specification of Rabs in compartments designated as follows: endocytotic vesicles, posterior potential recycling vesicles, lyso/phagosomes, all phagosomes, selected phagosomes and cytoproct-associated phagosomes with 4, 4, 1, 1, 6, and 3 Rab types, respectively, complemented by five Rabs associated with the oral apparatus (including the cytosome) and three associated with the cytoproct. Considering that, in P. tetraurelia, usually several similar ohnologs occur, the number of Rabs may be several times higher, although probably with redundant localizations and functions.

\subsubsection{Dense Core-Secretory Vesicle Biogenesis, Docking and Signaling for Exocytosis}

In ciliates, the endoplasmic reticulum is very elaborate, whereas the Golgi apparatus is inconspicuous; in Paramecium the Golgi apparatus is split in several hundred Golgi fields (dictyosomes) with very few membrane stacks (Allen 1988). Biogenesis of both, mucocysts and trichocyst, follows this classical assembly line. Precursor vesicles fuse and secretory proteins are trimmed (Briguglio et al. 2013; Gautier et al. 1994). When not posttranslationally cleaved, assembly to crystalline contents and transfer to the cell membrane are inhibited with both, mucocysts (Briguglio et al. 2013) and trichocysts (Pouphile et al. 1986; Gautier et al. 1994). Therefore, there must be a luminal signal, linked to a surface signal, for delivery along microtubules to the cell membrane.

Upon arrival at the cell membrane trichocysts induce restructuring of the docking site by formation of a "fusion rosette" (Beisson et al. 1976). The identity of the proteins forming a rosette is not clear (Plattner 2010a) although we know that its assembly requires the activity of the SNARE chaperone, NSF (Froissard et al. 
2002). One of the problems is that one rosette particle, to account for its diameter, would have to contain $\sim 70$ syntaxins (Plattner 2010b). Nevertheless, the t-/ Q-PtSyx1 can be safely assumed to occur at exocytosis sites although, by immunolocalization, it is scattered over the entire cell membrane (Kissmehl et al. 2007). No V0 parts of the $\mathrm{H}^{+}$-ATPase are seen at exocytosis sites (Wassmer et al. 2005), thus excluding a membrane fusion model involving these molecules (Plattner and Kissmehl 2003). The only v-/R-SNARE detected on the trichocyst membrane is PtSyb5 (Schilde et al. 2010). In T. thermophila, the Rab protein TtRabD41 has been detected at exocytosis sites (Bright et al. 2010).

$\mathrm{A} \mathrm{Ca}^{2+}$-sensor, type synaptotagmin, still requires identification and localization in ciliates. Such molecule is mandatory for rapid exocytosis - considering that all trichocysts can be rapidly released within 80 ms upon stimulation (Knoll et al. 1991b, Plattner et al. 1993) - the highest rate ever found with dense core-secretory organelles (Plattner and Kissmehl 2003). Candidate $\mathrm{Ca}^{2+}$-sensors found in the Paramecium genomic database have eight $\mathrm{C} 2$ domains (Kissmehl and Plattner unpubl. observ.), rather than the usual two, for high sensitivity $\mathrm{Ca}^{2+}$ binding (Südhof 2014). Such extended synaptotagmins (e-syts) also occur in other systems, up to mammalians, and they allow membrane-to-membrane links over a broader interspace (Pérez-Lara and Jahn 2015). This would fit the trichocyst-cell membrane interspace at docking sites. Another cursory note based on database mining indicates in $P$. tetraurelia occurrence of a homolog of DOC2.1-a two $\mathrm{C} 2$ domain-bearing $\mathrm{Ca}^{2+}$-binding protein in apicomplexan parasites (Farrell et al. 2012).

Figure 6.1d illustrates which additional proteins are assembled at, and around a trichocyst docking site. Calmodulin is required for the assembly of SNAREs (Kerboeuf et al. 1993). Specific isoforms of actin (Sehring et al. 2007a, b), together with a $63 \mathrm{kDa}$ phosphoprotein (pp63/parafusin, pf), phosphatase 2B (calcineurin), and $\mathrm{Ca}^{2+}$-inhibited protein kinase are distributed around trichocyst tips and the nearby subplasmalemmal space. They are considered important for energetic aspects of signaling during stimulated trichocyst exocytosis (Plattner and Kissmehl 2003). A plasmalemmal $\mathrm{Ca}^{2+}$-ATPase/pump serves for keeping subplasmalemmal $\mathrm{Ca}^{2+}$ concentration low, whereas a SERCA-type $\mathrm{Ca}^{2+}$-ATPase/pump refills the stores (see Plattner 2014). Upon stimulation, release of $\mathrm{Ca}^{2+}$ from alveolar sacs, the cortical $\mathrm{Ca}^{2+}$-stores (Stelly et al. 1991; Hardt and Plattner 2000), is mediated by ryanodine receptor-like protein (RyR-LP) channels (Ladenburger et al. 2009; Plattner 2015b). This microanatomical arrangement forces $\mathrm{Ca}^{2+}$ flux over trichocyst tips, thus mediating rapid response, as required for predator defence (Harumoto and Miyake 1991).

The CRCs, as well as the luminal high capacity/low affinity $\mathrm{Ca}^{2+}$-binding proteins are different in endoplasmic reticulum and in alveolar sacs, respectively. Other molecules of potential interest, such as a surface $\mathrm{Ca}^{2+} /$ polyvalent cation-sensing receptor and trimeric G-proteins are under debate. Such details concerning signaling in ciliates are discussed in a more extensive review (Plattner 2016).

Once an exocytotic pore is formed, $\mathrm{Ca}^{2+}$ can rapidly flow into the trichocyst lumen where it triggers the explosive decondensation (stretching) and release of the 
crystalline contents (Bilinski et al. 1981) by binding to specific secretory proteins (Klauke et al. 1998).

The $\mathrm{Ca}^{2+}$ signal flushing over exocytosis sites suffices to drive also exocytosis-coupled endocytosis of trichocyst "ghosts" and their internalization (Plattner et al. 1997), thus making these sites again available for docking of new trichocysts. After stimulation, in the cytosol, $\mathrm{Ca}^{2+}$ is most rapidly downregulated by binding to the $\mathrm{Ca}^{2+}$-binding protein, centrin (Sehring et al. 2009), whereas the pumps are primarily devoted to overall household regulation (Plattner 2016).

\subsubsection{Contractile Vacuole Complex}

This complex organelle is most dynamic, as it contracts and expands in $\leq 10 \mathrm{~s}$ intervals. From the contractile vacuole, radial canals emanate which are associated with a flexible three-dimensional network, the spongiome (Allen and Naitoh 2002). Its part proximal to the canals is smooth and periodically collapses after contraction (systole) and, thus, may represent a membrane reservoir for the expansion of the canals and of the vacuole during diastole. Canals are disconnected from the vacuole before every systole (Tominaga et al. 1998). In the electron microscope the peripheral part of the spongiome appears decorated by the head parts (V1) of the $\mathrm{H}^{+}$-ATPase (Fok et al. 2002; Wassmer et al. 2005) and, therefore, is called the decorated spongiome.

SNAREs (PtSyx2, 14, 15, and PtSyb2, 6, 9) and $\mathrm{Ca}^{2+}$-release channels (type PtCRC-II, i.e. inositol 1,4,5-trisphosphate receptors [ $\mathrm{InsP}_{3} \mathrm{Rs}$ ]) occur in different parts of the organelle in P. tetraurelia, together of PtSyx 2 and 15 as well as PtSyb2 and 9 at the vacuole outlet (the pore). Mechanosensitive $\mathrm{Ca}^{2+}$ channels occur in the database and are also localized to the contractile vacuole complex in other species. All this suggests the following signaling scenario (Plattner 2013, 2015c). (i) A proton gradient enables osmotic filling with water and ions from the cytosol (Allen and Naitoh 2002), including an excess of $\mathrm{Ca}^{2+}$ (Stock et al. 2002). (ii) Increasing turgor causes reversible rearrangement of membranes in the smooth spongiome with the help of SNAREs (Plattner 2013). (iii) Partial constitutive reflux of $\mathrm{Ca}^{2+}$ from the organelle through the $\mathrm{CRC}$-II/Ins $\mathrm{P}_{3} \mathrm{R}$-type channels into the nearby cytosol (Ladenburger et al. 2006) can drive membrane rearrangements in the smooth spongiome and vesicle fusion for ongoing protein replacement. (iv) Mechanosensitive channels may also mediate fusion of the vacuole with the cell membrane, thus opening the pore. (v) In $T$. thermophila, three Rab proteins have been detected, TtRabD2, 10 and 14 (Bright et al. 2010).

Before cytokinesis, de novo formation of additional contractile vacuole complexes is observed. Localization studies with ciliates and with other protozoa suggest signaling by proteins many of which are known to govern cytokinesis (Plattner 2015c). 


\subsection{Conclusions and Open Questions}

Despite considerable progress, there are important gaps in our knowledge about vesicle trafficking and underlying signaling mechanisms in ciliates although they now belong to the best analysed protozoa. In Paramecium, the abundance of ohnologs serves for a kind of gene amplification, but some may undergo neofunctionalization. It would be particularly rewarding to analyze the functional relevance of the unprecedented number of $\mathrm{H}^{+}$-ATPase a-subunits. May they serve for fine tuning of local signalling? Also important is the establishment of the identity of Rab target proteins. We also still have to learn a lot about the Golgi apparatus in ciliates.

Beyond these and some other gaps, many details of general validity about vesicle trafficking and underlying signaling mechanisms have been established specifically in ciliates, mainly with Paramecium and Tetrahymena. With P. tetraurelia our primary goal was to sound out, on a broad scale, the inventory available, while punctual scrutiny of some more important aspects was a secondary goal. Work may now be extended to detailed analysis of ciliate-specific aspects, as has been done for some important aspects, mainly with $T$. thermophila. Both systems together have taught us that signaling mechanisms underlying vesicle trafficking and beyond have been invented already at this level of evolution. The redundancy of structural elements, particularly in the cell cortex, and amplification effects of synchronized processes, such as synchronous exocytosis induction and synchronous reciliation after deciliation, can greatly facilitate the analysis of signalling processes.

\section{References}

Allen RD (1988) Cytology. In: Görtz HD (ed) Paramecium. Springer, Berlin, pp 440

Allen RD, Fok AK (2000) Membrane trafficking and processing in Paramecium. Int Rev Cytol 198:277 318

Allen RD, Naitoh Y (2002) Osmoregulation and contractile vacuoles of protozoa. Int Rev Cytol 215:351 394

Allen RD, Ma L, Fok AK (1993) Acidosomes: recipients of multiple sources of membrane and cargo during development and maturation. J Cell Sci 106:411 422

Aufderheide KJ (1977) Saltatory motility of uninserted trichocyst and mitochondria in Paramecium tetraurelia. Science 198:299 300

Beisson J, Jerka Dziadosz M (1999) Polarities of the centriolar structure: morphogenetic consequences. Biol Cell 91:367 378

Beisson J, Sonneborn TM (1965) Cytoplasmic inheritance of the organization of the cell cortex in Paramecium aurelia. Proc Natl Acad Sci USA 53:275 282

Beisson J, Lefort Tran M, Pouphile M, Rossignol M, Satir B (1976) Genetic analysis of membrane differentiation in Paramecium. Freeze fracture study of the trichocyst cycle in wild type and mutant strains. J Cell Biol 69:126 143

Bilinski M, Plattner H, Matt H (1981) Secretory protein decondensation as a distinct, $\mathrm{Ca}^{2+}$ mediated event during the final steps of exocytosis in Paramecium cells. J Cell Biol 88:179 188 
Bright LJ, Kambesis N, Nelson SB, Jeong B, Turkewitz AP (2010) Comprehensive analysis reveals dynamic and evolutionary plasticity of Rab GTPases and membrane traffic in Tetrahymena thermophila. PLoS Genet 6:e1001155

Briguglio JS, Kumar S, Turkewitz AP (2013) Lysosomal sorting receptors are essential for secretory granule biogenesis in Tetrahymena. J Cell Biol 203:537 550

Elde NC, Morgan G, Winey M, Sperling L, Turkewitz AP (2005) Elucidation of clathrin mediated endocytosis in Tetrahymena reveals an evolutionarily convergent recruitment of dynamin. PLoS Genet 1:e52

Farrell A, Thirugnanam S, Lorestani A, Dvorin JD, Eidell KP, Ferguson DJP, Anderson White BR, Duraisingh MT, Marth GT, Gubbels MJ (2012) A DOC2 protein identified by mutational profiling is essential for apicomplexan parasite exocytosis. Science 335:218 221

Flötenmeyer M, Momayezi M, Plattner H (1999) Immuno labeling analysis of biosynthetic and degradative pathways of cell surface components (glycocalyx) in Paramecium cells. Eur J Cell Biol 78:67 77

Fok AK, Allen PD (1993) Membrane flow in the digestive cycle of Paramecium. In: Plattner H (ed) Membrane Traffic in Protozoa. JAI Press, Greenwich (CT), London, pp 311337

Fok AK, Yamauchi K, Ishihara A, Aihara MS, Ishida M, Allen RD (2002) The vacuolar ATPase of Paramecium multimicronucleatum: gene structure of the B subunit and the dynamics of the V ATPase rich osmoregulatory membranes. J Eukaryot Microbiol 49:185 196

Frankel J (1973) Dimensions of control of cortical patterns in Euplotes Role of preexisting structure, clonal life cycle, and genotype. J Exp Zool 183:71 94

Froissard M, Kissmehl R, Dedieu JC, Gulk Krzywicki T, Plattner H, Cohen J (2002) $\mathrm{N}$ ethylmaleimide sensitive factor is required to organize functional exocytotic microdomains in Paramecium. Genetics 161:643 650

Gautier MC, Garreau De Loubresse N, Madeddu L, Sperling L (1994) Evidence for defects in membrane traffic in Paramecium secretory mutant unable to produce functional storage granules. J Cell Biol 124:893 902

Glas Albrecht R, Kaesberg B, Knoll G, Allmann K, Pape R, Plattner H (1991) Synchronised secretory organelle docking in Paramecium. Saltatory movement along microtubules transiently formed from ciliary basal bodies and selective exclusion of microinjected heterologous organelles. J Cell Sci 100:45 54

Griffiths GM, Tsun A, Stinchcombe JC (2010) The immunological synapse: a focal point for endocytosis and exocytosis. J Cell Biol 189:399 406

Grosshans BL, Ortiz D, Novick P (2006) Rabs and their effectors: achieving specificity in membrane traffic. Proc Natl Acad Sci USA 103:11821 11827

Hardt M, Plattner H (2000) Sub second quenched flow/X ray microanalysis shows rapid $\mathrm{Ca}^{2+}$ mobilization from cortical stores paralleled by $\mathrm{Ca}^{2+}$ influx during synchronous exocytosis in Paramecium cells. Eur J Cell Biol 79:642 652

Harumoto T, Miyake A (1991) Defensive function of trichocysts in Paramecium. J Exp Zool 260:8492

Hay JC (2007) Calcium: a fundamental regulator of intracellular membrane fusion? EMBO Rep $8: 236240$

Hurtado Lorenzo A, Skinner M, El Annan J, Futai M, Sun Wada GH, Bourgoin S, Casanova J, Wildeman A, Bechoua S, Ausiello DA, Brown D, Marshansky V (2006) V ATPase interacts with ARNO and Arf6 in early endosomes and regulates the protein degradative pathway. Nature Cell Biol 8:124 136

Husser MR, Hardt M, Blanchard MP, Hentschel J, Klauke N, Plattner H (2004) One way calcium spill over during signal transduction in Paramecium cells: from the cell cortex into cilia, but not in the reverse direction. Cell Calcium 36:349 358

Kerboeuf D, Le Berre A, Dedieu JC, Cohen J (1993) Calmodulin is essential for assembling links necessary for exocytotic membrane fusion in Paramecium. EMBO J 12:3385 3390

Kissmehl R, Schilde C, Wassmer T, Danzer C, Nühse K, Lutter K, Plattner H (2007) Molecular identification of 26 syntaxin genes and their assignment to the different trafficking pathways in Paramecium. Traffic 8:523 542 
Klauke N, Plattner H (1997) Imaging of $\mathrm{Ca}^{2+}$ transients induced in Paramecium cells by a polyamine secretagogue. J Cell Sci 110:975 983

Klauke N, Kissmehl R, Plattner H, Haga N, Watanabe T (1998) An exocytotic mutant of Paramecium caudatum: membrane fusion without secretory contents release. Cell Calcium 23:349 360

Knoll G, Haacke Bell B, Plattner H (1991a) Local trichocyst exocytosis provides an efficient escape mechanism for Paramecium cells. Eur J Protistol 27:381 385

Knoll G, Braun C, Plattner H (1991b) Quenched flow analysis of exocytosis in Paramecium cells: time course, changes in membrane structure and calcium requirements revealed after rapid mixing and rapid freezing of intact cells. J Cell Biol 113:1295 1304

Ladenburger EM, Plattner H (2011) Calcium release channels in Paramecium. Genomic expansion, differential positioning and partial transcriptional elimination. PLoS ONE 6(11): e27111

Ladenburger EM, Korn I, Kasielke N, Wassmer T, Plattner H (2006) An Ins $(1,4,5) \mathrm{P}_{3}$ receptor in Paramecium is associated with the osmoregulatory system. J Cell Sci 119:3705 3717

Ladenburger EM, Sehring IM, Korn I, Plattner H (2009) Novel types of $\mathrm{Ca}^{2+}$ release channels participate in the secretory cycle of Paramecium cells. Mol Cell Biol 29:3605 3622

Mellman I (1992) The importance of being acid: the role of acidification in intracellular membrane traffic. J Exp Biol 172:39 45

Miao W, Xiong J, Bowen J, Wang W, Liu Y, Braguinets O, Grigull J, Pearlman RE, Orias E, Gorovsky MA (2009) Microarray analyses of gene expression during the Tetrahymena thermophila life cycle. PLoS ONE 4:e4429

Neher E (1998a) Usefulness and limitations of linear approximations to the understanding of $\mathrm{Ca}^{++}$ signals. Cell Calcium 24:345 357

Neher E (1998b) Vesicle pools and $\mathrm{Ca}^{2+}$ microdomains: new tools for understanding their roles in neurotransmitter release. Neuron 20:389 399

Pérez Lara A, Jahn R (2015) Extended synaptotagmins (e syts): architecture and dynamics of membrane contact sites revealed. Proc Natl Acad Sci USA 112:4837 4838

Plattner H (2010a) Membrane trafficking in protozoa: SNARE proteins, $\mathrm{H}^{+}$ATPase, actin, and other key players in ciliates. Int Rev Cell Mol Biol 280:79 184

Plattner H (2010b) How to design a highly organized cell: an unexpectedly high number of widely diversified SNARE proteins positioned at strategic sites in the ciliate, Paramecium tetraurelia. Protist 161:497 516

Plattner H (2013) The contractile vacuole complex its expanding protein inventory. Int Rev Cell Mol Biol 306:371 416

Plattner H (2014) Calcium regulation in the protozoan model cell, Paramecium tetraurelia. J Eukaryot Microbiol 61:95 114

Plattner H (2015a) Calcium signalling in the ciliated protozoan model, Paramecium: strict signal localisation by epigenetically controlled positioning of different $\mathrm{Ca}^{2+}$ channels. Cell Calcium $57: 203213$

Plattner H (2015b) Molecular aspects of calcium signalling at the crossroads of unikont and bikont eukaryote evolution the ciliated protozoan Paramecium in focus. Cell Calcium 57:174 185

Plattner H (2015c) The contractile vacuole complex new cues to function and biogenesis. Crit Rev Microbiol 41:218 227

Plattner H (2016) Signaling in ciliates: long and short range signals and molecular determinants for cellular dynamics. Biol Rev (in press). doi:10.1111/brv.12218

Plattner H, Kissmehl R (2003) Dense core secretory vesicle docking and exocytotic membrane fusion in Paramecium cells. Biochim Biophys Acta (Mol Cell Res) 1641:183 193

Plattner H, Klauke N (2001) Calcium in ciliated protozoa: sources, regulation, and calcium regulated cell functions. Int Rev Cytol 201:115 208

Plattner H, Verkhratsky A (2013) $\mathrm{Ca}^{2+}$ signalling early in evolution all but primitive. J Cell Sci 126:2141 2150

Plattner H, Verkhratsky A (2015) The ancient roots of calcium signalling evolutionary tree. Cell Calcium 57:123 132 
Plattner H, Knoll G, Pape R (1993) Synchronization of different steps of the secretory cycle in Paramecium tetraurelia: trichocyst exocytosis, exocytosis coupled endocytosis and intracel lular transport. In: Plattner H (ed) Membrane traffic in protozoa. JAI Press, Greenwich (CT), London, pp 123148

Plattner H, Braun C, Hentschel J (1997) Facilitation of membrane fusion during exocytosis and exocytosis coupled endocytosis and acceleration of "ghost" detachment in Paramecium by extracellular calcium. A quenched flow/freeze fracture analysis. J Membr Biol 158:197 208

Plattner H, Westphal C, Tiggemann R (1982) Cytoskeleton secretory vesicle interactions during the docking of secretory vesicles at the cell membrane in Paramecium tetraurelia cells. J Cell Biol 92:368 377

Pouphile M, Lefort Tran M, Plattner H, Rossignol M, Beisson J (1986) Genetic dissection of the morphogenesis of exocytosis sites in Paramecium. Biol Cell 56:151 162

Rothman JE (2014) The principle of membrane fusion in the cell (Nobel lecture). Angew Chem Int Ed 53:12676 12694

Schilde C, Wassmer T, Mansfeld J, Plattner H, Kissmehl R (2006) A multigene family encoding R SNAREs in the ciliate Paramecium tetraurelia. Traffic 7:440 455

Schilde C, Schönemann B, Sehring IM, Plattner H (2010) Distinct subcellular localization of a group of synaptobrevin like SNAREs in Paramecium tetraurelia and effects of silencing SNARE specific chaperone NSF. Eukaryot Cell 9:288 305

Sehring IM, Reiner C, Mansfeld J, Plattner H, Kissmehl R (2007a) A broad spectrum of actin paralogs in Paramecium tetraurelia cells display differential localization and function. J Cell Sci 120:177 190

Sehring IM, Mansfeld J, Reiner C, Wagner E, Plattner H, Kissmehl R (2007b) The actin multigene family of Paramecium tetraurelia. BMC Genomics 8:82

Sehring IM, Klotz C, Beisson J, Plattner H (2009) Rapid downregulation of the $\mathrm{Ca}^{2+}$ signal after exocytosis stimulation in Paramecium cells: essential role of a centrin rich cortical filamentous network, the infraciliary lattice. Cell Calcium 45:89 97

Simon M, Plattner H (2014) Unicellular eukaryotes as models in cell and molecular biology: critical appraisal of their past and future value. Int Rev Cell Mol Biol 309:141 198

Stelly N, Mauger JP, Claret M, Adoutte A (1991) Cortical alveoli of Paramecium: a vast submembranous calcium storage compartment. J Cell Biol 113:103 112

Stock C, Grønlien HK, Allen RD (2002) The ionic composition of the contractile vacuole fluid of Paramecium mirrors ion transport across the plasma membrane. Eur J Cell Biol 81:505 515

Südhof TC (2014) The molecular machinery of neurotransmitter release (Nobel lecture). Angew Chem Int Ed 53:12696 12717

Tominaga T, Allen RD, Naitoh Y (1998) Electrophysiology of the in situ contractile vacuole complex of Paramecium reveals its membrane dynamics and electrogenic site during osmoregulatory activity. J Exp Biol 201:451 460

Wassmer T, Froissard M, Plattner H, Kissmehl R, Cohen J (2005) The vacuolar proton ATPase plays a major role in several membrane bounded organelles in Paramecium. J Cell Sci 118:28132825

Wassmer T, Kissmehl R, Cohen J, Plattner H (2006) Seventeen a subunit isoforms of Paramecium V ATPase provide high specialization in localization and function. Mol Biol Cell 17:917 930

Wassmer T, Sehring IM, Kissmehl R, Plattner H (2009) The V ATPase in Paramecium: Functional specialization by multiple gene isoforms. Pflugers Arch Eur J Physiol (invited review) 457:599 607

Wloga D, Frankel J (2012) From molecules to morphology: cellular organization of Tetrahymena thermophila. Meth Cell Biol 109:83 140 